\title{
REGULARITIES IN THE ARC SPECTRUM OF HAFNIUM $\left(\mathrm{Hf}_{\mathrm{I}}\right)$
}

By William F. Meggers and Bourdon F. Scribner

\section{ABSTRACT}

The first regularities among lines characterizing the first spectrum of hafnium $\left(\mathrm{Hf}_{\mathrm{I}}\right)$ have been discovered. Combinations of seven low energy levels with higher excited states account for more than 200 lines. Inner quantum numbers have been assigned to the energy levels and a tentative identification of the seven low levels is suggested.

As soon as new descriptions of hafnium arc and spark spectra were completed ${ }^{1}$ the authors attempted to find regularities among the lines. Our first attempt to classify $\mathrm{Hf}_{\mathrm{I}}$ lines was not successful, but a wave-number system containing $206 \mathrm{Hf}_{\mathrm{II}}$ lines was established without great difficulty. These first regularities in the spark spectrum of hafnium were published last year. ${ }^{2}$ Encouraged by the results obtained with $\mathrm{Hf}_{\mathrm{II}}$ lines, attention was again turned to the $\mathrm{Hf}_{\mathrm{I}}$ lines; a recurring difference of $1,071 \mathrm{~cm}^{-1}$ was found, but no further progress was made. It must be remembered that Zeeman effects, temperature classification, absorption data, and similar descriptive information which have aided in the analysis of other complex spectra were entirely lacking for Hf spectra and we had to depend solely on the combination principle as a criterion for classification. Very recently King has published ${ }^{3}$ the results of an investigation on the furnace spectrum of hafnium. On account of the high boiling point of $\mathrm{Hf}$, relatively high temperature is required to excite its spectra, and King was able to observe only a small portion of the complete arc spectrum. But King's descriptions of furnace spectra have always been of great importance in the analysis of spectra, and it is a pleasure to testify that this applies also to his results with the $\mathrm{Hf}_{\mathrm{I}}$ spectrum.

The general procedure in constructing a wave-number system for a complex spectrum was briefly outlined in our paper on the $\mathrm{Hf}_{\mathrm{Ix}}$ spectrum (loc. cit.). In our preliminary attempts to find regularities among $\mathrm{Hf}^{1}$ lines, we confined attention to differences less than 2,000 $\mathrm{cm}^{-1}$, and thereby unwittingly shut ourselves off from the solution of our problem. When King's data on the furnace spectrum became available we made another attack on the structure of the spectrum by systematically subtracting from each other the vacuum wave numbers of all low-temperature lines (Classes II and III). This immediately led to the recognition of two important wave-number

1 Meggers, B. S. Jour. of Research (R. P. 8), 1, p. 151; 1928.

2 Meggers and Scribner, J. Opt. Soc. Am. \& Rev. Sci. Inst., 17, p. 83; 1928.

3 King, Astrophys. J. 70, p. 105; 1929. 
intervals, viz, 2,356.6 and $2,211.0 \mathrm{~cm}^{-1}$. These then became the nucleus of a significant wave-number system which by successive addition of other levels finally became the 2-dimensional matrix given in Table 1. In this table the relative values for seven levels (A, B, C . . .) of low-energy content are printed at the top and the derived values for 63 higher states $(1,2,3,4 \ldots$. . ) on the left margin. The level values are followed by a number (inclosed in brackets) which represents the value of the inner quantum number, which has been tentatively assigned to each level. Assuming that our level A has $j=2$, the relative values of the inner quantum numbers for other levels are derived from the observed combinations which appear in the body of the table, remembering that a combination is permitted only for changes of \pm 1 or 0 in the value of $j$. Owing to the relatively small number of low-energy levels which we have thus far established, it is not always possible to assign a final value of $j$ to each of the higher levels, and in such cases corrections may be necessary.

The combinations of energy levels in Table 1 are represented by vacuum wave numbers of observed spectral lines. Above each wave number is the measured wave length, followed (in parentheses) by the estimated intensity and the temperature class. When temperature class accompanies intensity the data are quoted from King; otherwise the intensities are taken from Meggers. In general, King's estimated intensities exceed those of Meggers in the ultra-violet, but are about the same for visible lines. There appears to be a discontinuity in King's temperature classes in the ultra-violet at 2,860 A. All lines of shorter wave length are indicated as belonging to Classes IV or V, but our analysis show that many of these lines involve the low levels which otherwise predominantly give lines of Classes II or III. The tendency for temperature class to increase as the energy of the metastable levels increases is quite marked; it may be regarded as evidence that the levels are correctly oriented. It may be remarked that Table 1 includes a large majority of the stronger $\mathrm{Hf}_{\mathrm{I}}$ lines; only one low-temperature line, 3,057.02 A (100 II) remains, and it is quite probable that it is a single combination of a level having $j=5$ with the low $\mathrm{C}$ level, $j=4$. The total number of lines classified in Table 1 is 218 , four of which have been used twice. The average deviation of the observed wave numbers from the computed differences of the energy levels is only $0.05 \mathrm{~cm}^{-1}$, which corresponds to an average error of less than 2 parts in 1,000,000 in the wave-length determinations of these lines. Somewhat better agreement between observed and calculated wave numbers of $\mathrm{Hf}_{\mathrm{I}}$ lines as compared with the classified $\mathrm{Hf}_{\mathrm{II}}$ lines is due to the fact that the center of gravity of the former group is of greater wave length, for which the same error in wave length corresponds to a smaller error in wave number. 


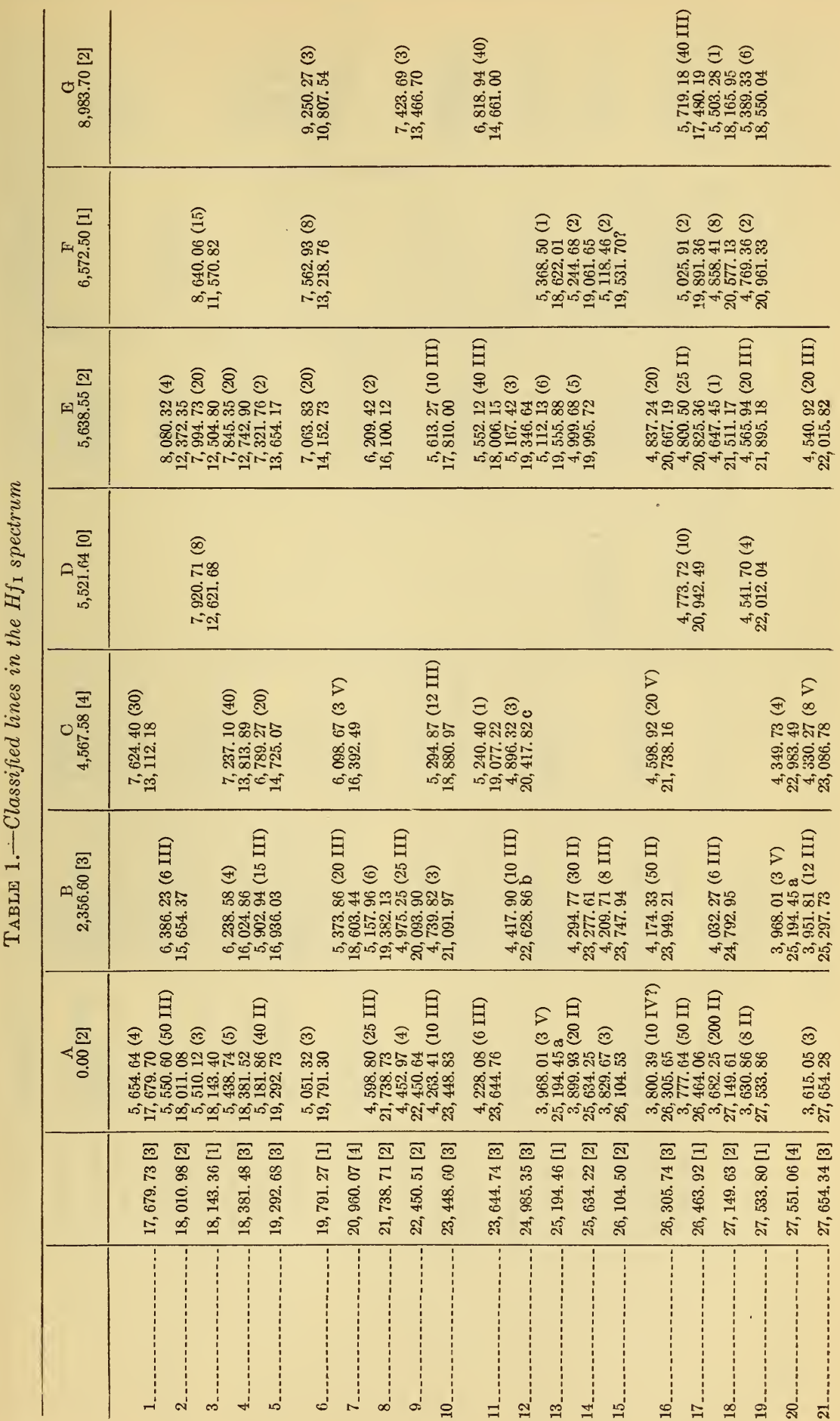




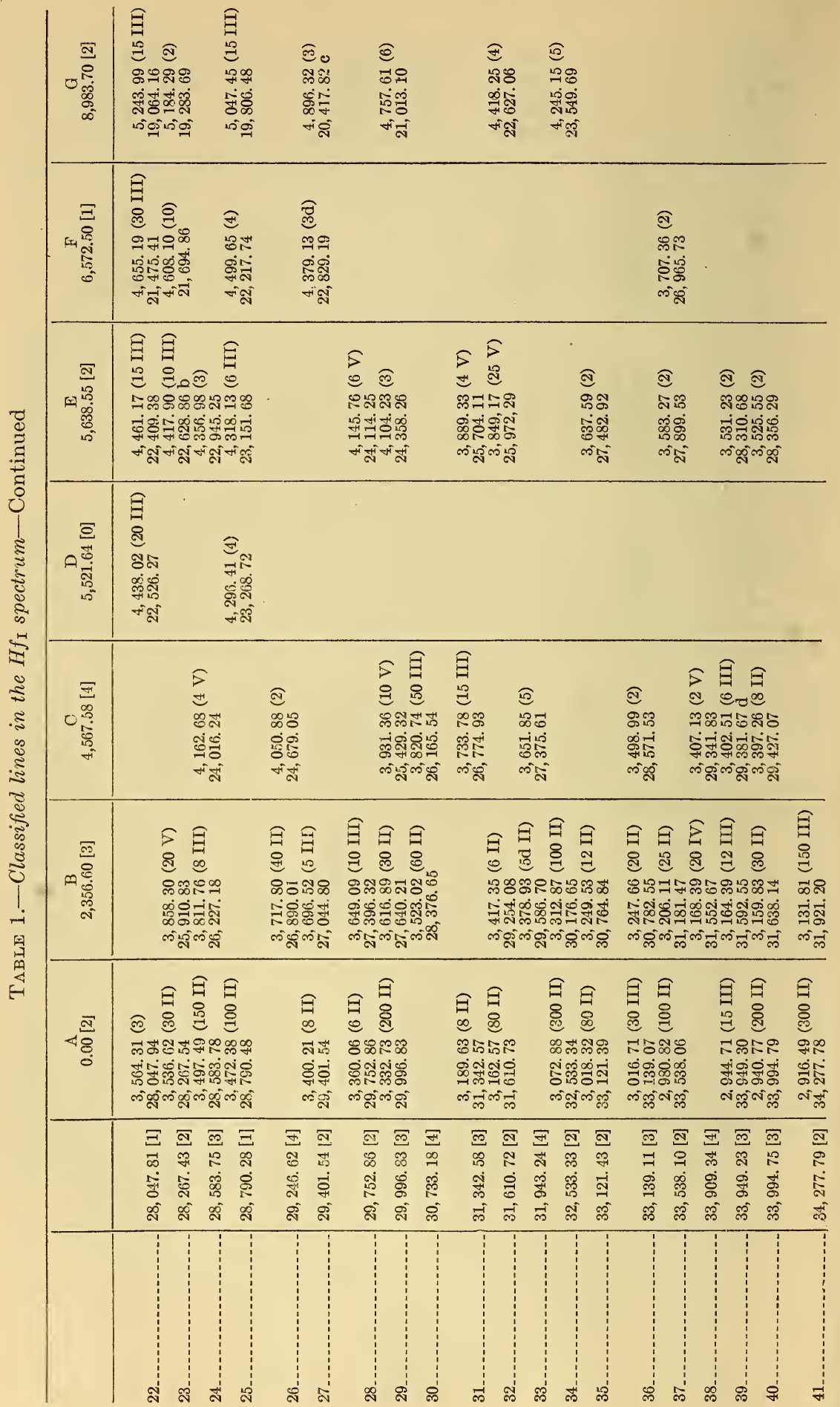


Scribner

\begin{tabular}{|c|c|c|c|c|c|}
\hline 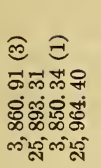 & 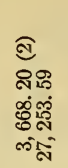 & 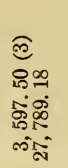 & 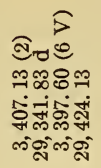 & 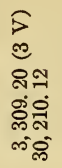 & 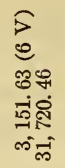 \\
\hline
\end{tabular}

\begin{tabular}{|c|c|c|c|c|}
\hline 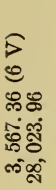 & 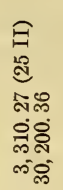 & 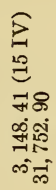 & 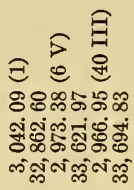 & 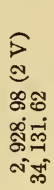 \\
\hline
\end{tabular}

\begin{tabular}{|c|c|c|c|c|c|c|}
\hline 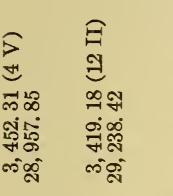 & 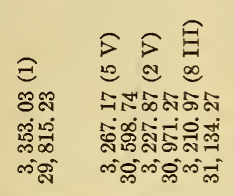 & & 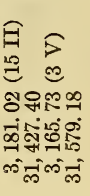 & 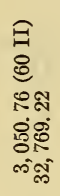 & 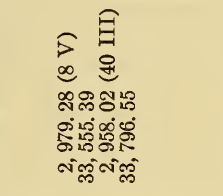 & 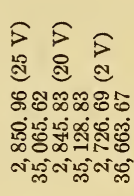 \\
\hline 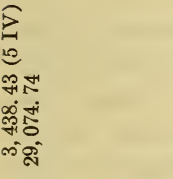 & & 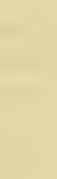 & & & & 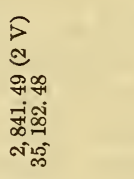 \\
\hline 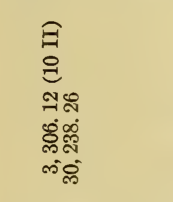 & 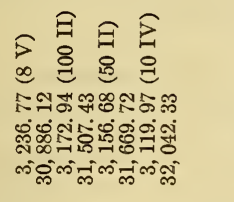 & 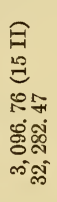 & & 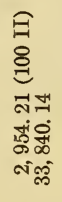 & 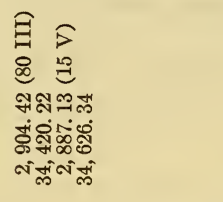 & 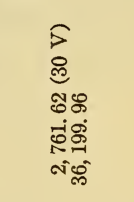 \\
\hline 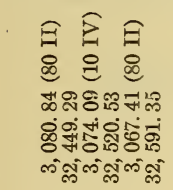 & 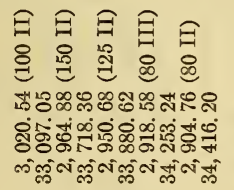 & 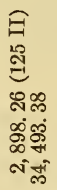 & 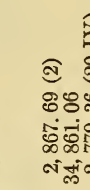 & 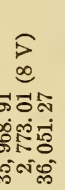 & 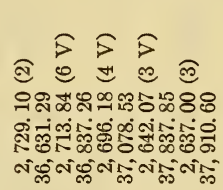 & 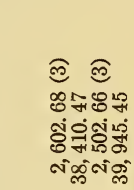 \\
\hline
\end{tabular}

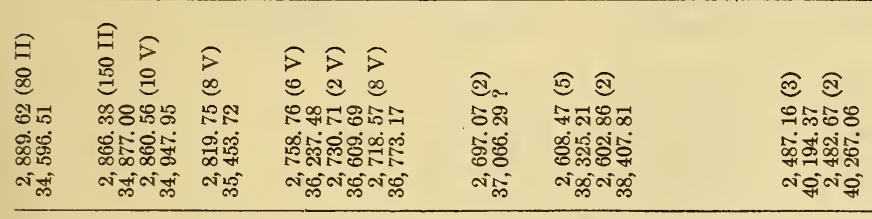

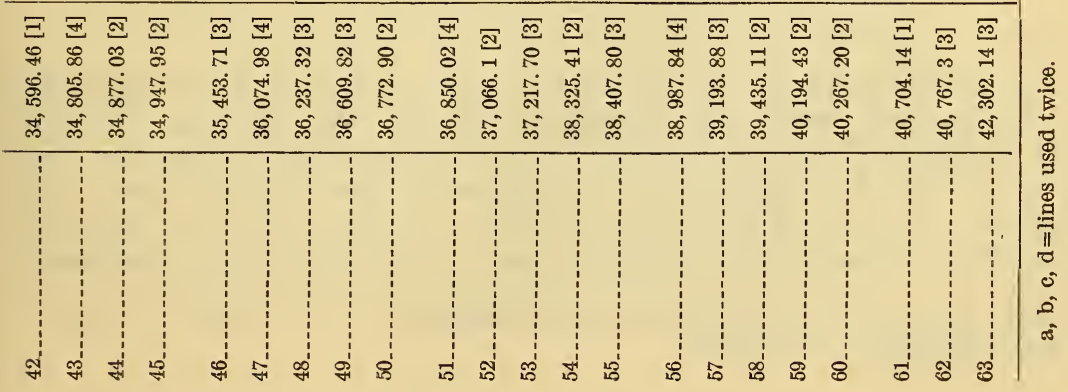


The Hf atom has 72 electrons $(Z=72)$, but only 4 are concerned with the production of the first optical spectrum. The 4 valence electrons are normally in $5 d$ and $6 s$ orbits, either $d^{2} s^{2}$ or $d^{3} s$. According to Hund's theory, ${ }^{4}$ these configurations of valence electrons can produce the following low-energy spectral terms:

\begin{tabular}{|c|c|c|c|}
\hline $\begin{array}{l}\text { Electron con- } \\
\text { figuration- }\end{array}$ & \multicolumn{3}{|c|}{ Spectral terms } \\
\hline $\begin{array}{l}d^{2} s^{2} \\
d^{3} s\end{array}$ & $\begin{array}{l}{ }^{1} \mathrm{G}_{4} \\
{ }^{3} \mathrm{H}_{4}, 5,6 \\
{ }^{2} \mathrm{D}_{1}, 2,3 \\
{ }^{1} \mathrm{H}_{5} \\
{ }^{1} \mathrm{D}_{2}\end{array}$ & $\begin{array}{l}{ }^{3} \mathrm{~F}_{2,3,4} \\
{ }^{1} \mathrm{D}_{2} \\
{ }^{5} \mathrm{~F}_{1,2,3,4,5} \\
{ }^{3} \mathrm{~F}_{2,3}, 4 \\
{ }^{3} \mathrm{~F}_{2}, 3,4 \\
{ }^{3} \mathrm{G}_{3}, 4,5 \\
{ }^{3} \mathrm{D}_{1,2,3} \\
{ }^{1} \mathrm{G}_{4} \\
{ }^{1} \mathrm{D}_{2}\end{array}$ & $\begin{array}{l}{ }^{3} \mathrm{P}_{0,1,2}{ }^{1} \mathrm{~S}_{0} \\
{ }^{5} \mathrm{P}_{1,2,3} \\
{ }^{5} \mathrm{P}_{1,2}, 3 \\
{ }^{3} \mathrm{P}_{0}, 1,2 \\
{ }^{3} \mathrm{~F}_{2}, 3,4 \\
{ }^{3} \mathrm{P}_{0}, 1,2 \\
{ }^{1} \mathrm{~F}_{3} \\
{ }^{1} \mathrm{P}_{1}\end{array}$ \\
\hline
\end{tabular}

The total number of levels thus predicted is 47 , nearly seven times as many as we have found. Comparison with the analogous $\mathrm{Ti}_{\mathrm{I}}$ and $\mathrm{Zr}_{\mathrm{I}}$ spectra which have been very completely analyzed by Russell ${ }^{5}$ and by Kiess, ${ }^{6}$ respectively, shows, however, that only a small part of these theoretical levels are important in the production of the strongest lines. For purposes of comparison and discussion the low terms of the three spectra are collected in Table 2.

TABLE 2.-Low levels in $T i_{I}, Z r_{I}$, and $H f_{I}$ spectra

\begin{tabular}{|c|c|c|c|}
\hline & $\mathrm{Ti}_{\mathrm{r}}$ & $Z_{r_{I}}$ & $\mathrm{Hf}_{\mathrm{x}}$ \\
\hline${ }^{3} \mathrm{~F}_{2}$ & 0.00 & 0.00 & 0.00 \\
\hline${ }^{3} \mathrm{~F}_{3}$ & 170.14 & 570.41 & $2,356.60$ \\
\hline${ }^{3} \mathrm{~F}_{4}$ & 386.88 & $1,240.84$ & $4,567.58$ \\
\hline${ }^{1} \mathrm{D}_{2}$ & $7,255.29$ & -54.70 & $5,638.55$ \\
\hline${ }^{8} \mathrm{P}_{0}^{\prime}$ & $8,436.69$ & $4,196.85$ & $5,521.64$ \\
\hline${ }^{3} \mathrm{P}_{1}^{\prime}{ }_{1}$ & $8,492.48$ & $4,376.28$ & $6,572.50$ \\
\hline${ }^{3} \mathrm{P}_{2}^{\prime}$ & $8,602.42$ & $4,186.11$ & $8,983.70$ \\
\hline $5 \mathrm{~F}_{1}^{\prime}$ & $6,556.86$ & $4,870.53$ & \\
\hline${ }^{5} \mathrm{~F}^{\prime}$ & $6,598.83$ & $5,023.41$ & \\
\hline $5 \mathrm{~F}^{\prime \prime}$ & $6,661.00$ & $5,249.07$ & \\
\hline $\begin{array}{l}{ }^{5} \mathrm{~F}^{\prime}{ }_{5}^{5} \mathrm{~F}^{\prime} \\
{ }^{2}\end{array}$ & $6,742.79$ & $5,540.54$ & \\
\hline${ }^{\circ} \mathrm{F}^{\prime} 5$ & $6,843.00$ & $5,888.93$ & \\
\hline
\end{tabular}

The identification of the $\mathrm{Hf}_{\mathrm{I}}$ levels is only tentative; it was suggested by comparison with the analogous $\mathrm{Ti}_{\mathrm{r}}$ and $\mathrm{Zr}_{\mathrm{I}}$ spectra. In each case a triplet $\mathrm{F}$ term is involved in the production of the strongest lines; in the $\mathrm{Ti}_{\mathrm{I}}$ spectrum, ${ }^{3} \mathrm{~F}_{2}$ represents the normal state (zero excitation energy) of the atom. In $\mathrm{Zr}_{\mathrm{I}}$ a singlet-D term is (slightly) lower than ${ }^{3} \mathrm{~F}_{2}$, and in $\mathrm{Hf}_{\mathrm{r}}$ we may thus expect to find ${ }^{1} \mathrm{D}_{2}$ considerably

4 Hund, Linienspektren und periodisches System der Elemente, p. 158, Julius Springer, Berlin; 1927.

8 Russell, Astrophys. J., 66, p. 388; 1927.

6 Kiess, unpublished. 
lower than ${ }^{3} \mathrm{~F}_{2}$. In our $\mathrm{Hf}_{\mathrm{rI}}$ paper, attention was called to a similar tendency of the doublet-D term in the analogous spark spectra, $\mathrm{Ti}_{\mathrm{II}}, \mathrm{Zr}_{\mathrm{II}}, \mathrm{Hf}_{\mathrm{II}}$. Although a lower singlet-D term in the $\mathrm{Hf}_{\mathrm{I}}$ spectrum has been sought, it has thus far evaded us.

In $\mathrm{Ti}_{\mathrm{I}}$ the intervals between the sublevels of ${ }^{3} \mathrm{~F}$ are ${ }^{3} \mathrm{~F}_{3}-{ }^{3} \mathrm{~F}_{2}=170$, ${ }^{3} \mathrm{~F}_{4}-{ }^{3} \mathrm{~F}_{3}=217$, which are exactly in the ratio of 3 to 4 , in agreement with Landé's interval rule. ${ }^{7}$ This interval rule is not strictly fulfilled in $\mathrm{Zr}_{\mathrm{r}}$, where the intervals in question are 570 and 670 , and the deviation becomes still greater in $\mathrm{Hf}_{\mathrm{I}}$, with intervals 2,356.6 and 2,211.0. If, however, the sums of the intervals or range of ${ }^{3} \mathrm{~F}$ levels in the three spectra are compared, we find $\mathrm{Zr} / \mathrm{Ti}=3.2$ and $\mathrm{Hf} / \mathrm{Zr}=3.6$, which leads us to believe that our interpretation of the first three levels (A. B. C. ...) in the $\mathrm{Hf}_{\mathrm{I}}$ spectrum may be correct.

In general, low or metastable ${ }^{3} \mathrm{P}$ terms in complex spectra follow the interval rule fairly closely. Thus in $\mathrm{Ti}_{\mathrm{I}}$ the ratio ${ }^{3} \mathrm{P}_{1}-{ }^{3} \mathrm{P}_{0} /{ }^{3} \mathrm{P}_{2}-{ }^{3} \mathrm{P}_{1}$ is almost exactly $1: 2 . \quad \mathrm{Zr}_{\mathrm{I}}$ appears to offer an exception, but we are nevertheless inclined to interpret our levels $\mathrm{D}, \mathrm{F}, \mathrm{G}$ in the $\mathrm{Hf}_{\mathrm{I}}$ spectrum as ${ }^{3} \mathrm{P}$, since the inner quantum numbers appear to be $0,1,2$, and the intervals are in the ratio $1: 2.1$.

The remaining level, $\mathrm{E}$, may be interpreted as a singlet-D level, although probably not the lowest one of this type. A quintet-F term provides some important metastable levels in both the $\mathrm{Ti}_{\mathrm{I}}$ and $\mathrm{Zr}_{\mathrm{I}}$ spectra, but we have been unable thus far to find the homologous term in the $\mathrm{Hf}_{\mathrm{I}}$ spectrum. In the absence of Zeeman effects, no attempt is made to name any of the higher terms of the $\mathrm{Hf}_{\mathrm{I}}$ spectrum. The authors plan to investigate the magnetic resolution of the $\mathrm{Hf}$ lines, but on account of the abnormal magnetic splitting factors $(g)$ which may be expected we are not optimistic about the value of such observations except for identifying the low-energy levels.

Washington, November 16, 1929.

7 Landé, Zeitschr. f. Phys., 15, p. 189; 1923.

$84789^{\circ}-29-12$ 